\title{
Application of System Dynamics and WCCl in Water Resources Evaluation: Taking Pakistan as an Example
}

\author{
Hong Fang a, * \\ College of Science, Huazhong Agricultural University, Wuhan, China \\ *, a 42540871@qq.com
}

Keywords: Water carrying capacity index, World Water Day.

\begin{abstract}
The theme of World Water Day in 2015 is water and sustainable development, which arouse our great attention to clean water scarcity. There are two models in this paper. Model one is the application of system dynamics in water resources. Aimed at the dynamic nature, the main factors of level, rate and auxiliary are carefully selected. Therefore, the recursive equations are set up based on the numerical relationship and time relationships. Model two is an evaluation model. Before applying it to assessment, a consistency check is performed with entropy and proves fruitful in water resources. Then some main levels like population, available water resources are determined from the system dynamics model above to construct the water carrying capacity index (WCCI).Taking Pakistan as an example, we have done the calculation, and the calculation results show the feasibility of the method.
\end{abstract}

\section{Introduction}

Early in 1956, Forrester, a professor in MIT, put forward system dynamics. It was originally used in corporate activities like production and inventory management. Using system simulation, the system dynamics can analyze the complicated feedbacks. It emphasizes that the system behavior is determined by internal mechanism. So the result is available as long as the eternal connections are well arranged. It has the advantages in nonlinear and time variant, thus widely used in resource and environment fields.

The evaluation of clean water supply capacity can't be performed just by a simple model. As a whole, water resources supply-demand system has a complexity among internal variables, external variables and interactions between foregoing two. To be specific, there is a variety of complicated connections in aggregate supply and its forces, aggregate demand and its forces, end even feedbacks of reciprocal causation. Therefore, a general approach is not detailed enough to assess the ability of a country to provide clean water to meet its needs, but a methodology with intricate architecture. Then a dynamic structure is needed when solving a conundrum like this. Hence, system dynamics is taken to deduce the dynamic process before establishing a model for assessment.

\section{Casual Loop Diagrams and System Dynamics}

The basic components of system dynamics is two parts: flow and elements. The flow consists of material flow and information flow while the element is made of level, rate, auxiliary and constant. Besides, there are three objects, causal loop diagram, flow graph and equation set, in system dynamics. Casual loop diagram and flow graph are the primary tools used in this part and can clearly depict the mazy causality and sophisticated concepts. And equation set is mainly formed by differential equations while difference equations are used to connect the rates and levels [1].The general process of system dynamics is itemized as below.

\subsection{Defining the Boundaries}

The boundary is the demarcation line between inclusion and exclusion of research subjects. By separating the irrelevant variables, the diagram is simplified and it can more concentrating on what we need. Generally, urban water system is divided into three subsystems: water supply and demand, sewage reclaiming and management and rainfall drainage management [2].Hereby, with all subsystems fully taken into account and the simplified flow graph is shown in Fig.1. 


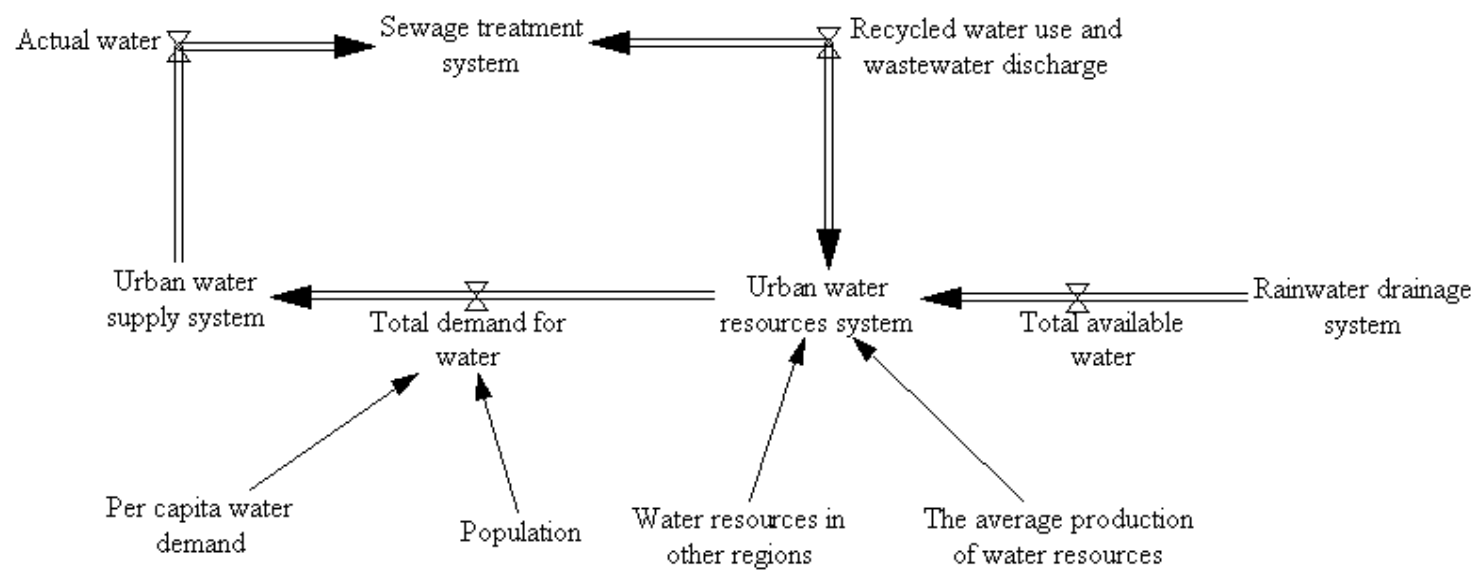

Figure 1. The simplified flow graph of the three subsystems.

\subsection{Determining the Factors For the System}

After defining the boundary of the system, it is easy to determine the concerned. As is explained above, the elements consists of level, rate, auxiliary and constant. So we attentively choose the typical factors of each element [3], as is shown in Table 1.

Table 1 . The factor of each element in system.

\begin{tabular}{cr}
\hline classification & factors \\
level & $\begin{array}{c}\text { Precipitation, population, integrated water quota per capita, sewage discharge rate, sewage treatment rate, } \\
\text { renewable proportion, available water resources }\end{array}$ \\
rate & $\begin{array}{r}\text { immigration, consumption change rate, discharge change, treatment change, renewable resources change } \\
\text { proportion, regeneration rate }\end{array}$ \\
auxiliary & $\begin{array}{r}\text { Treatment difference, sewage treatment, actual water consumption, the first balance between supply and } \\
\text { demand, the second balance between supply and demand, total water demand, water resources of other } \\
\text { countries renewable resources, water development intensity }\end{array}$ \\
constant & $\begin{array}{c}\text { Growth rate of population, discharge change rate, optimal sewage treatment rate, national water } \\
\text { production, water resources regeneration coefficient, development and utilization coefficient }\end{array}$ \\
\hline
\end{tabular}

\subsection{Drawing the Casual Loop Diagram and Flow Graph}

Having determined the boundary and factors, the research subjects is extremely apparent. The casual loop diagram and flow graph can be drawn by means of arranging the feedback loops. In doing so, the two diagrams is portrayed as Fig.2. 


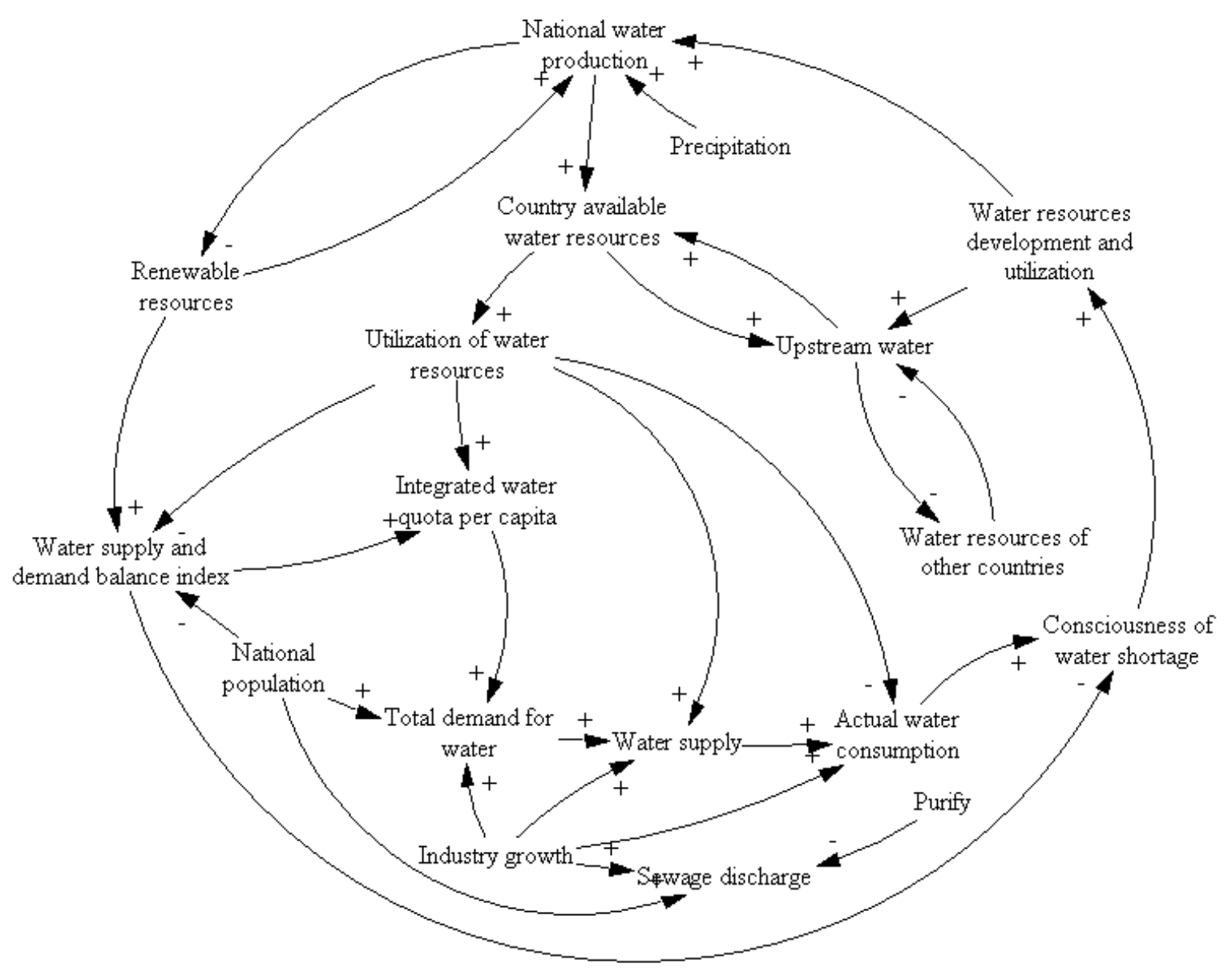

Figure 2. The casual loop diagram of the system.

\subsection{Listing the Equation Set}

Equation set is a series of formulas based on flow graph. It's essentially using discrete models to simulate the continuous system. To reflect the dynamic natures, the equations established are supposed to contain timestamps, from which it can implement the recursive computation. We synthetically think over the connections among factors and diagram.

In subsystem of water demand, there is a formula set as below:

(Total demand of water)t=(integrated municipal water quota capita) $\mathrm{t} \times($ population $) \mathrm{t}$

$$
\text { + (agricultural water)t +(industrial water)t +(service industry water)t }
$$

(Integrated water quota capita) $t=I N T E G$ (variation rate of water consumption) $\left.\right|^{\mathrm{T}}+$ initial value (Population) $\mathrm{t}=$ (population) $\mathrm{t}-1 \times($ population growth $) \mathrm{t}$

In subsystem of water exploitation, there is a formula set as below:

(Country available water resources) $t=$ initial value $+($ precipitation $) t+($ water purification $) t$

$$
\begin{aligned}
& + \text { (water transfer) } t+(\text { seawater desalination }) t-\text { (consumption)t } \\
& + \text { INTEG (the rate of renewable resources) }\left.\right|_{t} ^{\mathrm{T}}
\end{aligned}
$$

(The rate of renewable resources) $t=$ (renewable coefficient) $t \times($ renewable resources $) t$

(Renewable resources) $t=$ (water production) $t$ - (total water resources) $t$

(Actual utilization ratio of water resources) $t=$ (country available water resources precipitation) $t$

$$
\times \text { (Development intensity) } t
$$

In subsystem of reclaimed water, there is a formula set as below:

(Regeneration ratio) $\mathrm{t}=$ initial value+INTEG(regeneration ratio) $\left.\right|_{\mathrm{t}} ^{\mathrm{T}}$

(Sewage treatment $) \mathrm{t}=($ total demand for water $) \mathrm{t} \times$ treatment coefficient $\times$ emission coefficient

Treatment coefficient=initial value+INTEG(treatment change rate) $\left.\right|_{\mathrm{t}} ^{\mathrm{T}}$ 
(Reclaimed water) $\mathrm{t}=($ regeneration ratio $) \mathrm{t} \times($ sewage quantity $) \mathrm{t}$

(Treatment difference)t $=$ optimal treatment rate-(sewage treatment ratio)t

Emission coefficient=initial value+INTEG (emission change rate) $\left.\right|_{\mathrm{t}} ^{\mathrm{T}}$

(Emission change $) \mathrm{t}=($ emission change rate $) \mathrm{t} \times($ sewage emission rate $) \mathrm{t}$

In subsystem of water supply and demand, there is a formula set as below:

The first balance between supply and demand $=$ (total water demand) $t-$ (total water resourses) $t$

The second balance between supply and demand= (total water demand) $t$

- (Actual water consumption) $t$-(renewable resources) $t$

All our factors in Table 1 are contained in the formula set above, so do the timestamps. Actually, the dynamic process can be demonstrated by successive iteration. Therefore, given the indispensable parameters, any index can be deduced.

\section{Evaluation of Clean Water Supply Capacity}

When it comes to assess the water supply capacity, an index is required to be more objective. Based on the analysis of the foregoing factors and reference to relevant literatures, we ultimately adopted the Water Carrying Capacity Index (WCCI).

\subsection{WCCI Index}

The expression of WCCI [4] is defined as:

$$
\mathrm{WCCI}=\frac{\mathrm{p} \times \mathrm{wpc}}{\mathrm{w}}
$$

Where p denotes the population, wpc represents the integrated water quota capita and $\mathrm{w}$ is the available water resources.

Integrating the expression above and factors in Table 1, WCCI and system dynamics are easily to be linked up and used in system dynamics. As such, the evaluation index and foregoing model are tightly combined. So our assessment has the advantages of dynamic natures as well.

\subsection{Criterion}

To evaluate the situation whether the water supply capacity of a region is healthy or not,now we itemized the criterion of WCCI and shows in Table 2.

Table 2. The criterion of WCCI.

\begin{tabular}{ccc}
\hline WCCI & situation & water carrying capacity \\
\hline$[0.00,0.33)$ & surplus & heavily surplus \\
{$[0.33,0.50)$} & & moderately surplus \\
{$[0.50,0.67)$} & mildly surplus \\
{$[0.67,1.00)$} & balance & close to surplus \\
{$[1.00,1.33)$} & & close to overload \\
{$[1.33,2.00)$} & mildly overload \\
{$[2.00,5.00)$} & overload & moderately overload \\
{$[5.00,+\infty)$} & & heavily overload \\
\hline
\end{tabular}

When WCCI is lower than 0.67 , there is a capacity of surplus. Water is adequate in these areas and it can load the further development of population and economics.

When WCCI is higher than 0.67 but no larger than 1.33 , there is a capacity of balance. There are basic equilibrium between supply and demand when the water situation is in balance. Water capacity ought to be paid attention to and it is necessary to coorinate the relationships among population, society and economics in region like this.

When WCCI is greater than 1.33, there is a capacity of overload. Water resource is seriously inadequate. What's worse, there exit conflicts between folks and water. The development of economics and society is severely constrained by the shortage of water. Water transferring and renewable exploitation is of great significance.

Given indispensable parameters, WCCI can be calculated by system dynamics, and then correspond the value in Table 2 to find out its water carrying capacity. 


\section{Water Resources Evaluation in Pakistan}

As is reported by International Monetary Fund(IMF),Pakistan has become one of the most water-poor nations with 1017 cubic meter water available per head, which results in severe desolation over 20 million acre land desolate. IMF also urges that the shortage of water has resulted in great loss in Pakistan which will severely limits economic growth greatly. Moreover, for lack of price system of water supply in Pakistan and advanced infrastructure, water is essentially free [5], which leads to tremendous waste. In a word, Pakistan has much room to explore in water resources.

\subsection{Clean Water Supply Capacity of Pakistan By WCCI}

We have made an evaluation model above to assess whether a region has the ability to provide clean water and meet its need or not. To verify our model, most of the related data are collected from the World Bank and so on. As for those missing ones, they could be interpolated by cubic spline interpolation. The data from 2008 to 2014 are applied to system dynamics, and then the WCCI in recent years are calculated and itemized in Table 3.

Table 1. The WCCI of Pakistan in 2005-2014.

\begin{tabular}{ccc}
\hline year & WCCI & water carrying capacity \\
\hline 2008 & 6.50 & heavily overload \\
2009 & 7.01 & heavily overload \\
2010 & 9.75 & heavily overload \\
2011 & 10.24 & heavily overload \\
2012 & 8.80 & heavily overload \\
2013 & 10.59 & heavily overload \\
2014 & 11.48 & heavily overload \\
\hline
\end{tabular}

Based on the analysis of Table 3,the WCCI index these years in Pakistan is increasing year by year and all of them are greater than 5.The result suggests that the water resources in Pakistan is heavily overloaded and is even more daunting, which agrees with the actual conditions and proves our model fruitful.

\subsection{Reason Analysis of Water Scarcity in Pakistan}

It has been testified that Pakistan is a heavily overloaded country in water resources. There are two primary causes for water scarcity: physical scarcity and economic scarcity [6]. What follows is the reason analysis by addressing the two drivers.

Physical scarcity is where there is inadequate water in a region to meet the demand of its population and economics. The definition can be decomposed into two parts: water resources and consumption of a region, where water resources are mainly determined ty geographical conditions and climatic conditons. At first, two thirds of territories in Pakistan lie in arid desert plain while another one third of that is in mountain areas. It's an extreme arid country with over $90 \%$ of its areas situated in semiarid regions or arid zones. Therefore, the geographical conditions in Pakistan are terrible to an extent. Secondly, located in the south Asia subcontinent crossed by tropic of cancer and a low-pressure center, the Southwest Monsoon is almost inaccessible to Pakistan, thus the whole country is hot with high evaporation and low precipitation, which makes its natural conditions, water resources particularly, more formidable. At last, different from other countries, there is a peculiar water consumption structure with $95 \%$ of its freshwater used in agriculture in Pakistan. What's worse, Pakistan government implements the free basic-water supply policy, which further amplifying the consumption of water.

Economic scarcity can be explained by western microeconomics. Thus economic indicators like price are used to discuss its scarcity. It is known that when demand exceeds supply, the price of goods or services wil rise and when oversupply, inversely. In what follows, we consider the water supply and demand respectively. The indicators we selected to reflect the water demand is GDP, while those of supply are available water, sewage discharge and sewage treatment capability. There are several feedbacks among the factors above. We can learn that the growth of increases the sewage discharge, which in turn inhibit the development of GDP; the sewage discharge promotes the sewage treatment 
capacity, thereby increases the available water resources. The adequate water resource is conducive to economics. In short, there are close connections among the indicators.

\section{Conclusion}

Based on the qualitative and quantitative analysis above, several conclusions are drawn as below. Firstly, water resource in Pakistan is heavily overloaded years ago and has the tendency of further deterioration if nothing is done. Secondly, both the physical scarcity and economic scarcity are the reasons to explain why Pakistan is water scarcity. Thirdly, on the basis of physical scarcity, the water banks in Pakistan is not abundant because of its uqique geographical factors and climatic factors while the consumption is extreme large for lack of effective price mechanism and backward infrastructure. Lastly, economic scarcity indicates that GDP is the most influential factor, followed by sewage treatment capacity and available water resources, and sewage discharge has the minimal impact.

\section{References}

[1]. Bo Zhang,Chaohui Yu,Qiang Sun,Shun Li,Mingxiang Huang,Overview of system dynamics and related software,Environment and Sustainable Development.2(2010)1-3.

[2]. Bagheri A,Hjorth P,A framework for process indicators to monitor for sustainable development,Environment Development\&Sustainability.9(2007)143-161.

[3]. Yi Yun,Zhihong Zou,Huiwen Wang,Analysis on Beijing's urban water resource demand-supply system,Mathematics in Practice and Theory.12(2011)129-136.

[4]. Shicun Xu,Research of carrying capacity of water resources of Jinlin province,Jilin University.2009.

[5]. http://world.people.com.cn/n/2015/0609/c157278-27126981.html.

[6]. Wenjun Hu,Jiangji Yang,Heqing Huang,Lessons and inspirations from international cooperation and dispute resolution on water resources development in the indus River Basin,Resources Science.10(2010)1918-1925. 